\title{
Decision-making capacity in adults: its assessment in clinical practice
}

\author{
John Bellhouse, Anthony Holland, \\ Isobel Clare \& Michael Gunn
}

In English Law, an adult has the right to make decisions affecting his or her own life, whether the reasons for that choice are rational, irrational, unknown or even non-existent. This right remains even if the outcome of the decision might be detrimental to the individual ( $\operatorname{Re} T$ (Adult: Refusal of Treatment), 1992) or to a viable foetus (Re S (Adult: Refusal of Medical Treatment), 1992). However, such a right to self-determination is meaningful only if the individual is appropriately informed, has the ability (capacity) to make the decision and is free to decide without coercion (Grisso, 1986).

The concept of capacity lies at the heart of an adult's right to make legally significant decisions such as giving or withholding consent to treatment, making a will, entering into a contract and marrying (see British Medical Association \& Law Society, 1995). In recent years, its meaning has been explored within English law in several important legal cases (e.g. Re C (Adult: Refusal of Medical Treatment), 1994; Re T (Adult: Refusal of Treatment), 1992). It has also been explored in the scientific literature with reference to the law in the USA (Grisso \& Appelbaum, 1998) and Japan (Kitamura et al, 1998). A definition of incapacity has been produced in England and Wales (Law Commission, 1995), and this has been adopted in the Government's proposed legislation for decision-making on behalf of people without capacity, Making Decisions (Lord Chancellor, 1999). The Expert Committee on reform of the Mental Health Act (MHA) 1983 has recommended that a capacitybased approach to decisions about compulsory admission and treatment should be included in any new mental health legislation (Department of Health, 1999). The Expert Committee adopted the Law Commission's definition of capacity.

The emphasis of our article is practical, and it draws both on the literature (Grisso \& Appelbaum, 1998; Wong et al, 1999) and on our experience as practitioners and researchers. We consider two main issues. First, we discuss the legal concept of the capacity of adults in medicine, surgery and psychiatry (Shaw (2001) considers the legal situation regarding children and young people). Second, we present a framework for assessing capacity to consent to a health care intervention. We focus on a specific common situation - that of the 'patient' who refuses a proposed health care intervention (a more general discussion of capacity appears in Wong et al (1999)) and on English law. However, the general principles should apply to other legal systems with different criteria for defining capacity.

\section{The definition of capacity}

In England and Wales, as in most common-law jurisdictions, there is a 'presumption of capacity'. An adult is considered to have the capacity to give or withhold consent to a health care intervention until the contrary is proven. There is at present no statutory definition of capacity, but if the proposed

John Bellhouse is research registrar at the Section of Developmental Psychiatry, University of Cambridge (Department of Psychiatry, Section of Developmental Psychiatry, University of Cambridge, Douglas House, 18b Trumpington Road, Cambridge CB2 2AH), where he has studied the capacity of new admissions to psychiatric wards to consent to their admission and treatment. Tony Holland is a lecturer at the Department of Psychiatry, University of Cambridge, and a consultant psychiatrist with an interest in learning disabilities at Lifespan NHS Trust. Isobel Clare is a clinical and forensic psychologist at the Department of Psychiatry, University of Cambridge. Michael Gunn is Professor of Law and Head of the Department of Academic Legal Studies, Nottingham Law School, Nottingham Trent University. 
Box 1 The Law Commission's definition of incapacity

A person is without capacity if at the material time he or she is :

1. Unable by reason of mental disability to make a decision on the matter in question. That is if the disability is such that, at the time decision needs to be made, he or she is unable to:

understand relevant information; retain this information;

make a decision based on information given

2. Unable to communicate a choice on that matter because he or she is unconscious or for any other reason

(Law Commission, 1995: pp. 37-38)

Mental Incapacity Bill (Lord Chancellor, 1999) is enacted a definition of incapacity based on the work of the Law Commission (Law Commission, 1995) will be introduced (Box 1).

The Law Commission also makes the following points. First, adults who do not have a mental disorder cannot be considered to be without capacity. Second, 'mental disability' is defined as "any disability or disorder of the mind or brain whether permanent or temporary which results in a disturbance or impairment of mental functioning" (Law Commission, 1995: p. 36). Third, decision-making capacity should not be considered to be a stable, global characteristic that an individual with a mental disability either has or has not. It might vary depending on the subject of the decision and it might change over time. Moreover, it depends not only on the decision-maker but also on the characteristics of the decision, including its complexity and the way in which it is presented. Fourth, assessment of capacity should be based on the 'balance of probabilities'.

\section{Principles of capacity assessment}

There are three main approaches to the assessment of a person's decision-making capacity: the status, outcome and functional approaches (Wong et al, 1999). The main points of each are shown in Box 2 .
Box 2 Approaches to assessing decisionmaking capacity

Functional The components of the decisionmaking process are analysed

Outcome The quality of the decision-making process is rated on the basis of the projected consequences of the decision

Status An attribute of the decision-maker (e.g. a diagnosis) is used to evaluate the quality of the decision

A functional approach to the assessment of decision-making capacity is explicit in the Law Commission's recommendations and subsequent proposals (Law Commission, 1995: p. 32). Empirical studies have supported the feasibility of such an approach (Wong et al, 2000). However, status and outcome approaches are used at present and these will continue to play a role in new legislation. Under the provisions of the MHA 1983, it is the status of an individual (i.e., whether he or she has a mental disorder of a particular nature or degree) that determines whether his or her decision may be overridden. The person's capacity to make the decision does not have to be considered. There may be occasions when the outcome of a decision alerts the health care practitioner to the need for more detailed questioning of an individual's capacity (for example, if a person rejects prescribed medication after a long period of acceptance). However, in routine clinical practice such alerts usually arise only when medical advice is refused: the capacity of people who agree to treatment is rarely considered. The conundrum presented by adults who are without capacity in relation to a particular decision but are assenting, as in $R v$ Bournewood Community and Mental Health NHS Trust (1998), will be considered in a future issue of APT (Dickenson, 2001).

\section{Capacity and the Mental Health Act 1983}

The MHA 1983 does not require an assessment of capacity to determine the course of action with regard to a person refusing to agree to hospital admission or treatment for a mental disorder. The combined criteria of presence of a mental disorder (status), the nature and severity of that disorder and 
perceived outcome without intervention (risk) are relied on.

Although capacity assessment is therefore not central to the application of the MHA 1983, it is relevant to specific situations. The most frequent of these are the continuation of treatment beyond 3 months for detained patients (Section 58) and electroconvulsive therapy, both of which require either consent or the opinion of a second doctor appointed by the MHA Commission. In these contexts, it is clear that the patient must have the capacity to give or withhold consent (Jones, 1999). Under Section 57, treatments such as psychosurgery and the implantation of sex hormones require both consent (and capacity to consent) and the agreement of a second-opinion doctor.

The present situation, in which an adult with capacity can refuse treatment for a physical disorder, but not (if detained) for a mental disorder seems odd and, indeed, discriminatory. The case of $\operatorname{Re} C$ (Adult: Refusal of Medical Treatment (1994)) illustrates the point. The Court ruled that $\mathrm{C}$, who had gangrene of one leg, had the capacity to decide whether or not to consent to amputation. Since he withheld his consent to this treatment it could not lawfully proceed. In contrast, there was no requirement to assess his decision-making capacity with respect to treatment of his mental disorder, schizophrenia. He could be forced to have treatment for this under the MHA 1983, even though he might have had capacity to decide against it. The difference in criteria regarding consent for the two categories of health problem is of particular interest given that, in contrast to the gangrene, the schizophrenia was not thought to present any threat to C's life.

Thus, when considering the treatment of physical disorders the decision of a capable adult must be respected, even if the outcome is likely to be his or her death. In the case of a mental disorder, the MHA 1983 allows treatment without consent, even if the risks (e.g. to health) of not having treatment may be less serious and even if the person concerned has the capacity to make the decision.

In its proposals for reform of the MHA 1983 (Department of Health, 1999), the Expert Committee suggested that the inclusion of a capacity test would be consistent with one of its stated principles, that of non-discrimination, meaning that people with mental and with physical health problems should not be treated differently. The case for bringing all health care decisions within the same legislative framework has also been strongly argued by others (Szmukler \& Holloway, 2000; Zigmond \& Holland, 2000).

\section{Capacity in physical medicine}

The MHA 1983 defines the relationship between a person with a mental disorder and the medical practitioner proposing hospital treatment for that disorder. All other relationships between health care practitioners and their adult patients are governed by common law. Consent must be sought or treatment constitutes battery. Where consent cannot be given, owing to lack of capacity, the treating clinician must act in the person's 'best interests' (Re F (Mental Patient: Sterilisation), 1990a,b). The concept of decision-making capacity is therefore central to medical practice in the identification of those whose wishes must be respected and those whose wishes can, indeed should, be overridden in their own best interests when they lack capacity to decide.

\section{Capacity assessment in practice}

The assessment of capacity might best be understood in terms of a framework for evaluating the process by which a person makes a decision. This assessment takes place in the context of the proposed legal definition of capacity (Box 1), but is independent of the outcome of the decision. This demands a level of impartiality that may be difficult to attain in practice. Respect for people's decisions, however unwise they might appear, may be what the law requires in a given situation.

The issue of capacity and treatment refusal arises frequently in non-psychiatric practice. A psychiatrist may then be asked to give an opinion, for example regarding the role of psychiatric disorder in influencing a patient's decision-making ability. In such cases, it is important to remember that the decision whether or not to proceed with treatment remains with the treating doctor or other health practitioner.

There may be other reasons for psychiatric involvement in non-psychiatric cases. For example, a practitioner may believe that all non-compliance is a psychiatric issue or may misunderstand the role of the MHA in non-psychiatric practice. It is therefore important to be clear why a colleague is seeking a psychiatric opinion and to correct at an early stage any misconceptions. 
A lack of capacity to make a particular health care decision is only one possible explanation of a person's rejection of advice. An individual might not want the treatment, might have been poorly informed or might feel unable to make a decision because of anxiety about the treatment.

\section{Advising about capacity to make a health care decision}

In an emergency, the steps below may have to be compressed. The principles remain the same.

Being able to consent to a particular health care decision requires that the person concerned is, first, appropriately informed and, second, has the capacity to make a decision based on the relevant information. Thus, in determining whether a person has the capacity to make a particular decision practitioners must be aware of the relevant information themselves and be able to determine whether an individual has the ability to use that information to arrive at a decision and to communicate that choice. Therefore, the person responsible for treatment is usually involved in the assessment process, as he or she will be best informed about the nature of the treatment proposed and the risks and benefits of proceeding or not.

A patient making a particular health care decision needs to be made aware of the relevant facts. Box 3 lists the key information that the law requires be understood by the patient. It is important to be aware that the level of knowledge of the procedure in question is "in broad terms" and is not the level of knowledge considered essential in negligence cases (see Sidaway $v$ Board of Governors of Bethlem Royal and Maudsley Hospital, 1984). This is particularly important when considering the level of knowledge required of the risks of a procedure.

Box 3 Making a health care decision

To make a health care decision the individual must understand in broad terms:

The nature of the intervention

The purpose of the intervention

The risks and benefits of the intervention

The risks of not carrying out the intervention

The risks and benefits of alternative interventions
Deciding what to do when a patient will not cooperate with a capacity assessment can be difficult. The legal position that an adult is presumed to have capacity unless it is demonstrated otherwise must be balanced against the need to ensure that incapable people are not denied essential medical treatment. The urgency of the proposed treatment and the evidence pointing towards a disorder likely to affect a person's capacity must be taken into account.

\section{Determining capacity}

Although legislation requires that a patient has a broad understanding of a proposed treatment (Box 3 ), case law has never explicitly demanded that he or she understands the diagnosis. However, discussion of treatment requires preliminary discussion of the diagnosis. Thus, the patient should know, in broad terms, what illness he or she has or might have and appreciate that this information applies to him or her. An abstract grasp of the issues surrounding the treatment of cancer is not adequate if a patient with the disease denies the diagnosis. Implicit in understanding the pros and cons of treatment is a notion of the prognosis - again, in broad terms. For meaningful discussion of a proposed treatment to be possible, the patient should understand how he or she is most likely to change without it or with current management. Prognosis is less exact than diagnosis, but broad principles do apply. Serious outcomes, such as a high probability of death or stroke, must be explicitly understood.

Hospital admission can be considered as a special case, where the intervention is the admission itself. The information relevant to an admission decision has never been explored in English Law, but Hoge (1994) reviews this issue from an American perspective.

If a patient's understanding of the above issues differs from that of the body of medical opinion, it is important to probe the basis of this difference in detail. It is unacceptable for a finding of incapacity to be made without making every attempt to communicate the relevant knowledge (see Strategies to improve capacity).

\section{Assessment of mental state}

If the presence or absence of a mental disability has not already been established, psychiatric 
assessment will be necessary. The Law Commission's new proposals explicitly include disorders of the brain within the definition of mental disability. Assessment should concentrate on whether (and how) the features of an individual's mental disability might impinge on his or her capacity. It is helpful to focus on determinants of incapacity that relate to the known features of a disorder. For example, if there is a clear diagnosis of dementia, poor attention or memory might be the most obvious indicators of incapacity.

\section{Strategies to improve capacity}

When the urgency of the situation allows, and according to the circumstances, some or all of the following strategies should be considered to improve the patient's understanding of the treatment.

\section{Attention to communication problems}

It is essential that the person assessed can hear and see adequately. The advice of speech and language therapists might assist communication, for instance in those with dysphasia. A competent interpreter will be needed if the patient does not speak English and the psychiatrist does not speak the patient's native tongue. In borderline cases, where the command of English of a non-English speaker appears adequate but the treatment issues are not understood, an interpreter might reveal whether misunderstanding is due to the patient's poor English.

\section{Presenting information in a simpler form}

There is evidence that breaking information down helps people understand it better. In those with limited verbal skills, visual aids can improve understanding (Grisso \& Appelbaum, 1995; Wong et al, 2000).

\section{Treatment of mental disability}

It may be possible to defer decisions until treatment has improved an incapacitating disorder. The likely time span for improvement, the expected degree of improvement and its likely effect on capacity must be carefully considered.

\section{Dilemmas in capacity assessment}

Usually capacity assessment, like MHA assessment, is relatively clear-cut. However, a small proportion of situations are very difficult and in these the issues need careful consideration. The following are potentially problematic.

\section{The level of information required}

The legal definition of 'broad terms' may be hard to interpret in practice. Does comprehension of 'cancer' require the use of that word, or are 'swelling', 'growth', 'tumour' or 'neoplasm' adequate? Most would agree that implicit in the term cancer is malignancy, or potential for distant spread, and that this is not implicit in any of the other words. The treating doctor needs to determine the key components relevant to diagnosis and prognosis and to be sure that the terms used by both parties are properly understood.

\section{Pessimism}

Patients do not always see risk/benefit calculations in the same way that specialists do. Probability may be poorly understood and patients might be naturally pessimistic in their outlook. Pessimism may be due to a depressive disorder, in which case the influence of this mental disorder on the person's capacity must be evaluated. On the other hand, specialists may be overoptimistic in their evaluation of the success of their interventions.

\section{Abnormal mental experiences}

It will probably be simple to elicit and agree on the effect of cognitive impairment on decisionmaking capacity. However, the influence of grandiose thinking, delusional beliefs, depression, etc. may be more complex and open to different interpretations. This leads to the potential for less reliable and more contentious judgements about capacity.

\section{Religious and spiritual beliefs}

Refusal of a blood transfusion or other procedures owing to literal interpretation of texts relating to 
religious beliefs is not uncommon. A clear distinction between delusional belief and religious belief can be drawn by considering the history of a person's belief, his or her usual customs and the social recognition given to that particular faith. This interesting area is considered in detail by Waldfogel \& Meadows (1996).

\section{Avoiding coercion}

An important consideration is the question of 'voluntariness'. A patient should make a decision him- or herself. Difficulties can arise if people close to the patient have an undue, and perhaps unhelpful, influence over the patient and if the patient feels pressured to consent by professional staff. A supportive, private and non-judgemental atmosphere is essential.

\section{After the determination of decision-making capacity}

The process of capacity assessment should enable determination of whether a person with a particular mental disability is or is not able to make the decision in question. Where time allows, it may be possible to improve a person's decision-making capacity (e.g. by treating a mental disorder, giving speech and language therapy or using visual aids). However, once the judgement has been made the course of action will depend on whether the person has capacity or not.

\section{People with capacity who refuse treatment}

When a person has the capacity to make a health care decision and has decided to refuse an important intervention, it is good practice to provide the information in writing afterwards, for his or her reconsideration. Follow-up should be arranged with the relevant specialist, so the person has the opportunity to have a change of mind. Disagreement about the intended procedure should not mean that the individual is rejected by the treating team. The general practitioner should be told that treatment was offered and refused (rather than not having been given for some other reason).
Some treating doctors feel angry when a patient refuses an intervention and take the attitude that if patients do not follow their advice they can go elsewhere. However, there is a legal and moral imperative for health professionals to remain engaged. If a bad outcome ensues, it is important to know that everything possible was done to ensure that the patient received the best treatment in keeping with his or her wishes. For example, symptom relief should be offered where definitive treatment is refused.

\section{Treatment of people lacking capacity}

In English law there is no mechanism by which a relative or friend can make the decision lawfully on an adult's behalf. The treating doctor has a duty to act in the patient's best interests (Re F (Mental Patient: Sterilisation), 1990a,b). However, it is good practice to consult those close to the patient and to consider what is known about the patient's wishes. Before proceeding, the treating doctor must be satisfied that the treatment is in the patient's best interests and that it is the least invasive and/or the least restrictive alternative. This can be a difficult judgement that depends on the interplay of many factors, including the previous wishes of the patient (e.g. a valid advance directive made at a time when the patient had capacity). In carrying out treatment, practical issues can be as difficult as legal ones, especially when the patient puts up active physical resistance and the treatment is prolonged (e.g. administering solutions intravenously or oxygen by a mask).

The absence of any statute law in England and Wales that enables substitute decision-making means that there is no ready means of appeal if there is disagreement over what is in the patient's best interests. Mr. L in the Bournewood judgment $(R v$ Bournewood Community and Mental Health NHS Trust, 1998) lacked the capacity to give or refuse consent to hospital admission and the health professionals concerned arranged admission against the wishes of his paid carers. His initial admission was justified under common law, although subsequently he was placed under Section 3 of the MHA 1983 and on appeal was discharged to the care of his paid carers. This is evidence of a serious gap in mental health law that has been recognised by the House of Lords. The proposed Mental Incapacity Act may well resolve this issue, but at present there is no indication when such a Bill will be put before Parliament. 


\section{Record-keeping}

Issues relating to capacity are contentious and can be subject to a high degree of medico-legal scrutiny. A clear, precise and legible record is therefore very important. The final opinion and, above all, its rationale should be recorded in the notes in accordance with all the formalities of correct notemaking. It is important to record also the nature of any mental disorder or, where there is none, what steps were taken to exclude disorder. In the case of patients lacking capacity, it is important to record whether treatment of their mental disability might restore their capacity to make the decision and how long this might be expected to take.

\section{Conclusions}

The concept of decision-making capacity is central to the resolution of the tension that exists between, on the one hand, the principle of autonomy of the individual, and on the other, having the legal means to act on behalf of people who do not have the capacity to make specific health care decisions for themselves. All medical practitioners should understand the concept and have experience of its application in practice. The principles outlined above will help psychiatrists to make judgements of capacity when requested by colleagues and where required in their own practice. The most difficult situations will still be difficult, but a step-by-step exploration of the points above should make most decisions defensible.

The issue of individuals who accept treatment but lack capacity will continue to vex lawyers and policy-makers. In psychiatric practice, the refusal of treatment is a more pressing concern, and a focus on the decision-making process of those who refuse may make the psychiatrists' assessments simpler and more transparent. Issues of capacity and consent can be difficult and it is good practice to seek advice and discuss findings with colleagues, including those who are not medical practitioners. Legal advice may also be appropriate. In some situations the courts make the final decision (e.g., to allow a sterilisation operation).

The determination that a patient lacks the capacity to make a particular health care decision does not imply consent. It places a duty on the treating health care professional to determine and justify a course of action that is both in the patient's best interests and the least invasive and restrictive option, considering all relevant facts. Good practice includes consultation with family or carers, if time allows. If there is uncertainty the practitioner should err on the side of saving life but, in the case of physical disorder, a capable adult has the right to refuse treatment and this must be respected.

\section{References}

British Medical Association \& Law Society (1995) Assessment of Mental Capacity - Guidance for Doctors and Lawyers. London: BMA.

Department of Health (1999) Reform of the Mental Health Act 1983. London: Stationery Office.

Dickinson, D. (2001) Decision-making competence in adults: a philosopher's viewpoint. Advances in Psychiatric Treatment, 7 , in press

Grisso, T. (1986) Evaluating Competencies: Forensic Assessments and Instruments. New York: Plenum.

— \& Appelbaum, P. S. (1995) The MacArthur Treatment Competence Study. III. Abilities of patients to consent to psychiatric and medical treatments. Law and Human Behavior, 19, 149-173.

— \& - (1998) Assessing Competence to Consent to Treatment: A Guide for Physicians and Other Health Professionals. New York: Oxford University Press.

Hoge, S. (1994) On being "too crazy" to sign into a mental hospital: the issue of consent to psychiatric hospitalisation. Bulletin of the American Academy of Law and Psychiatry, 25, 531-540.

Jones, R. M. (1999) The Mental Health Act Manual (6th edn). London: Sweet and Maxwell.

Kitamura, F., Tomoda, A., Tsukada, K., et al (1998) Method for assessment of competency to consent in the mentally ill: rationale, development and comparison with the medically ill. International Journal of Law and Psychiatry, 21, 223-244.

Law Commission (1995) Mental Incapacity: A Summary of the Law Conmmission's Recommendations (LC231). London: Stationery Office.

Lord Chancellor (1999) Making Decisions. The Government's Proposal's for Makiing Decisions of Behalf of Mentally Incapacitated Adults: A report Issued in the Light of Responses to the Consulation Paper "Who Decides?" (Cm44650). London: Stationery Office.

Shaw, M. (2001) Competence and consent to treatment in children and adolescent. Advances in Psychiatric Treatment, 7, 150-159.

Szmukler, G. \& Holloway, F. (2000) Reform of the Mental Health Act: health or safety? British Journal of Psychiatry, 177, 196-200.

Waldfogel, S. \& Meadows, S. (1996) Religious issues in the capacity evaluation. General Hospital Psychiatry, 18, 173182.

Wong, J., Clare, I. C. H., Gunn, M., et al (1999) Capacity to make health care decisions: its importance in clinical practice. Psychological Medicine, 29, 437-446.

- - - Watson, P., et al (2000) The capacity of people with a "mental disability" to make a health care decision. Psychological Medicine, 30, 295-306.

Zigmond, A. \& Holland, A. J. (2000) Unethical mental health law: history repeats itself. Journal of Mental Health Law, 3 , $49-56$.

$R v$ Bournewood Community and Mental Health NHS Trust, ex parte L [1998] 3 AllER 289.

Re C (Adult: Refusal of Medical Treatment [1994] AllER 819.

Re F (Mental Patient: Sterilisation) [1990a] 2 AC 1.

Re F (Mental Patient: Sterilisation) [1990b] 4 BMLR 1. 
Re S (Adult: Refusal of Medical Treatment [1992] 4 AllER 671. Re T (Adult: Refusal of Treatment) [1992] 4 AllER 649.

Sidaway $v$ Board of Governors of Bethlem Royal and Maudsley Hospital [1984] 1 AllER 643.

\section{Multiple choice questions}

1. The capacity of the following adults to consent to treatment need not be considered:

a a person brought to casualty unconscious following a road accident

b a person newly detained under Section 3 of the MHA 1983 and refusing haloperidol to treat a manic state

c a person detained under Section 2 of the MHA 1983 and refusing antibiotics for pneumonia

$\mathrm{d}$ a person with depression refusing renal dialysis for chronic renal failure, as "it is no longer worth the effort"

e a prisoner serving a life sentence for murder refusing surgery for suspected peritonitis in an accident and emergency department.

2. The following are true of capacity as defined by the Law Commission:

a once a person lacks capacity, he or she is considered to be incapable for life

b a mental disorder, as defined by the Law Commission, is a necessary condition of incapacity

c an inability to make decisions regarding medical treatment does not mean that a person cannot make a will

$\mathrm{d}$ all capacity judgements must be made by a duly constituted court

e incapacity must be proven 'on the balance of probabilities'.

3. A patient must understand the following information in order to give valid consent to a treatment proposed by a health care professional:

a the purpose of the treatment

b who will administer the treatment

c the risks of the treatment

$\mathrm{d}$ the risks of doing nothing

e the cost of the treatment.
4. If an adult lacks the capacity to make health care decisions, the following are true:

a the patient's parents can give consent

b the courts must authorise treatment

c a doctor can lawfully proceed without consent if treatment is in the patient's best interests

$\mathrm{d}$ a valid advanced directive must be taken into account by the treating doctor

e radiotherapy cannot be given without valid contemporaneous consent.

5. If a capable adult refuses treatment for a medical or surgical condition, the following are true:

a a woman can be treated against her will in the interests of her viable foetus

b English law allows treatment refusal on religious grounds

c a psychiatric assessment is mandatory

d English law allows treatment to be refused even when the person's life is in danger

e the discovery that the person was coerced has no bearing on the validity of their consent.

\begin{tabular}{|llllllllll|}
\hline MCQ answers & & & & & & \\
1 & & 2 & & 3 & & 4 & & 5 & \\
a & F & a & F & a & T & a & F & a & F \\
b & T & b & T & b & F & b & F & b & T \\
c & F & c & T & c & T & c & T & c & F \\
d & F & d & F & d & T & d & T & d & T \\
e & F & e & T & e & F & e & F & e & F \\
\hline
\end{tabular}

